\title{
Spatial monsoon variability with respect to NAO and SO
}

\author{
S B KAKADE* and S S DUGAM \\ Indian Institute of Tropical Meteorology, Pune 411 008, India. \\ *e-mail: kakade@tropmet.res.in
}

In this paper, the simultaneous effect of North Atlantic Oscillation (NAO) and Southern Oscillation (SO) on monsoon rainfall over different homogeneous regions/subdivisions of India is studied. The simultaneous effect of both NAO and SO on Indian summer monsoon rainfall (ISMR) is more important than their individual impact because both the oscillations exist simultaneously throughout the year. To represent the simultaneous impact of NAO and $\mathrm{SO}$, an index called effective strength index (ESI) has been defined on the basis of monthly NAO and SO indices.

The variation in the tendency of ESI from January through April has been analyzed and reveals that when this tendency is decreasing, then the ESI value throughout the monsoon season (JuneSeptember) of the year remains negative and vice versa. This study further suggests that during the negative phase of ESI tendency, almost all subdivisions of India show above-normal rainfall and vice versa. The correlation analysis indicates that the ESI-tendency is showing an inverse and statistically significant relationship with rainfall over 14 subdivisions of India. Area wise, about $50 \%$ of the total area of India shows statistically significant association. Moreover, the ESI-tendency shows a significant relationship with rainfall over north west India, west central India, central north east India, peninsular India and India as a whole. Thus, ESI-tendency can be used as a precursor for the prediction of Indian summer monsoon rainfall on a smaller spatial scale.

\section{Introduction}

The Indian summer monsoon rainfall shows variability on different time and spatial scales. This increases the complexity in the prediction of Indian summer monsoon rainfall. Failure in monsoon prediction of the recent 2002 and 2004 drought years (Gadgil 2004) suggests the necessity to search for a new parameter, which along with the already existing parameters may improve the forecasting skill. The spatial variability in Indian summer monsoon rainfall affects agriculture and hence the total economy of India. In the present paper, an attempt has been made to explain the variability of Indian summer monsoon rainfall on a smaller spatial scale in relation to a new parameter based on NAO and SO. This study will be useful for the understanding of Indian summer monsoon rainfall variability and predicting it on a smaller spatial scale.
This study will also be useful to improve the skill of forecasting monsoon rainfall using the parameter discussed in this paper, along with the already existing parameters.

North Atlantic Oscillation (NAO) and Southern Oscillation ( $\mathrm{SO}$ ) are two large-scale atmospheric alterations in northern and southern hemispheres respectively. These two oscillations exist throughout the year simultaneously and are known to affect the Indian summer monsoon rainfall individually. Many earlier studies by Sikka (1980); Pant and Parthasarathy (1981); Shukla et al (1983); Rasmusson and Carpenter (1983); Verma (1990); Kripalani and Kulkarni (1997) have shown the effect of SO on the monsoon activity over India. Recently, Dugam et al (1997) have studied the effect of NAO on Indian summer monsoon rainfall. The study reveals an inverse relationship between NAO and Indian summer monsoon rainfall. All

Keywords. North Atlantic oscillation; southern oscillation; Indian summer monsoon rainfall; effective strength index. 


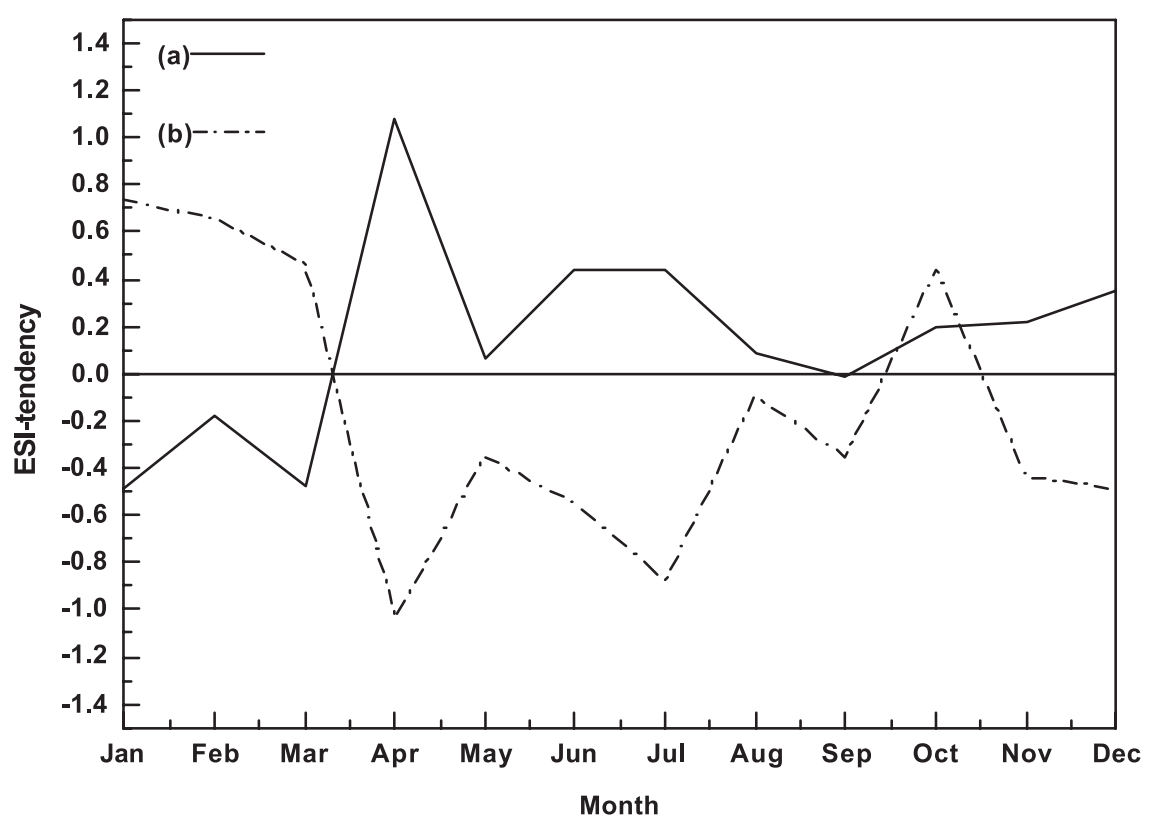

Figure 1. Monthly composite picture of ESI during (a) positive (28 years) and (b) negative (25 years) tendency of ESI from January to April during 1951-2002.

these studies are mainly confined to the individual effect of NAO and SO on Indian summer monsoon rainfall.

Van Loon and Rogers (1978); Chen (1982); Rojers (1984); Alexander and Elena (1992); Dugam and Kakade (1999); Hurrell (1996), etc. have suggested an interactive mechanism between these two oscillations. Moreover, the observational evidences (Kakade and Dugam 2000) of the behaviour of these two oscillations during contrasting monsoon years of India suggested the necessity to understand and consider the simultaneous impact of NAO and SO on Indian summer monsoon rainfall activity. In order to understand the simultaneous impact of NAO and SO on Indian summer monsoon rainfall, an index called effective strength index (ESI) has been defined based upon monthly indices of NAO and SO. This ESI is computed as: the algebraic difference between monthly indices of NAO and SO calculated for each month for the period 1951-2003. The deviation from the annual mean difference series, for the period 1951-95, is calculated for each month and this anomaly series is then normalized by the standard deviation of the annual mean difference series for the abovementioned period.

\section{Data used}

For this study the following data have been used:

- North Atlantic Oscillation (NAO): The NAO data have been taken from the web address www.cpc.ncep.noaa.gov.
- Southern Oscillation (SO): The SO data have been taken from the web address www.cpc.ncep.noaa.gov.

- Indian summer monsoon rainfall (ISMR): The summer monsoon rainfall (June-September) data for different subdivisions, homogeneous regions of India and India as a whole have been taken from the web address www.tropmet.res.in. The percentage departure of this data from long term mean is calculated and these indices are used for further analysis in this paper.

\section{Discussion}

Kakade and Dugam (2000) have suggested that during excess monsoon years the ESI decreases from January to April whereas during deficient monsoon years there is a rising tendency of ESI from January to April. Thus the tendency of ESI from January to April is the distinguishing character between excess and deficient monsoon activity over the Indian subcontinent. However, not every year is an extreme monsoon year and so we must see the variability of ESI-tendency and summer monsoon rainfall over different subdivisions and homogeneous regions of India. The tendency of ESI from January to April is computed as the difference between April-ESI and January-ESI.

During the recent 53-year period (1951-2003), there were 28 years when this tendency of ESI increased (positive) and 25 years when this ESItendency decreased (negative). Figure 1 depicts the monthly composite of ESI during the increasing 

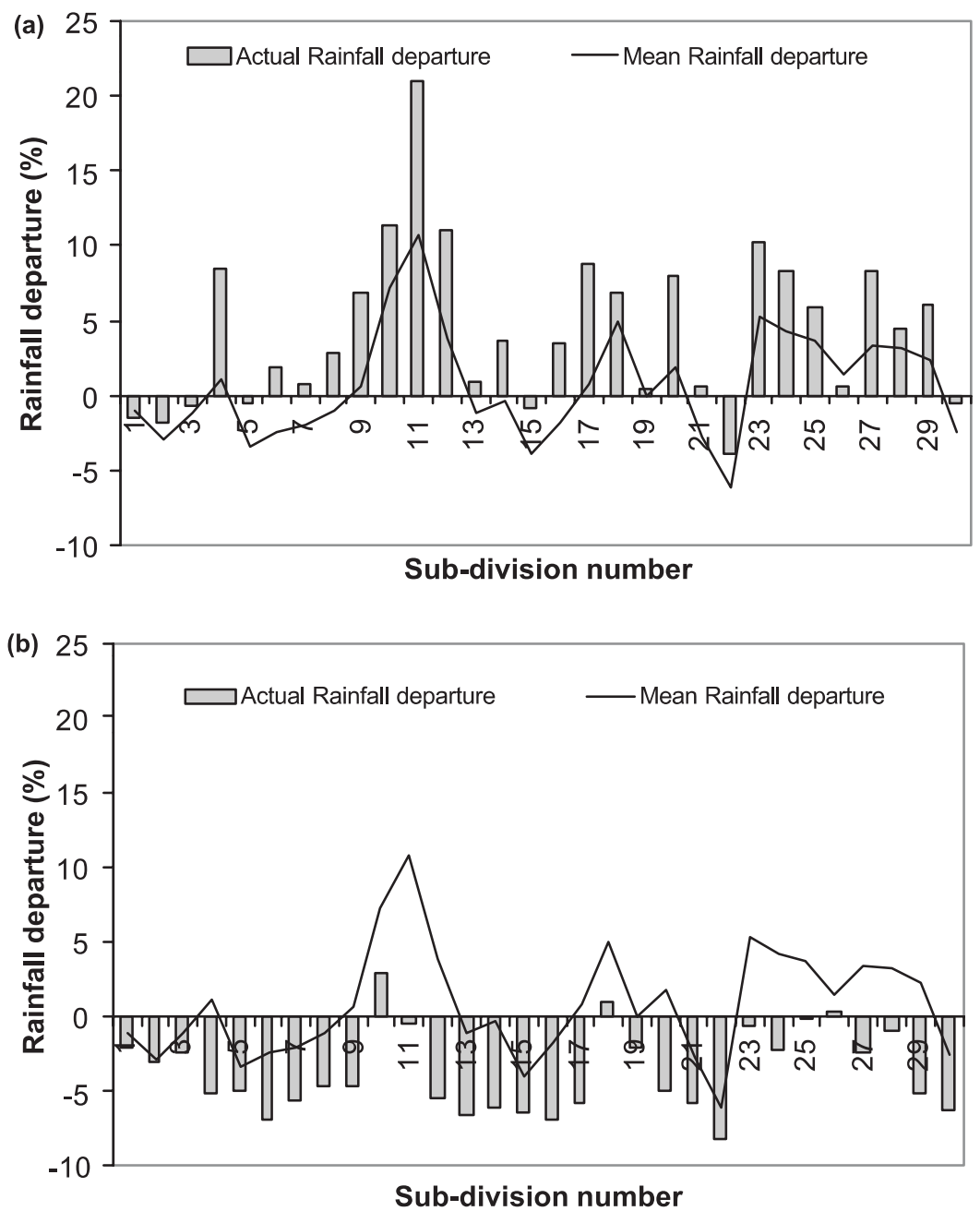

Figure 2. Composite picture of subdivisional percentage rainfall departures during (a) negative phase of E41 (25 years) and (b) positive phase of E41 (28 years).

and decreasing tendency of ESI. It reveals that when the tendency is positive, monthly ESI values are also positive during the monsoon season (JuneSeptember) of that year and vice versa. Thus the ESI-tendency indicates the phase of monthly ESI during that particular year and hence the simultaneous behaviour of two oscillations (NAO, SO) during and just before the beginning of the monsoon season. Figure 2 depicts the composite picture of subdivisional percentage rainfall departures during (a) negative phase of ESI-tendency (25 years) and (b) positive phase of ESI-tendency (28 years). It reveals that when ESI-tendency is negative, almost all subdivisions of India show above-normal (longterm average for 1951-2003) percentage rainfall departure and vice versa. Thus, ESI-tendency can suggest the performance of summer monsoon rainfall over different subdivisions of India in a qualitative way (above-normal or below-normal rainfall). In order to understand the relationship between ESI-tendency and summer monsoon rainfall over different subdivisions of India, quantitatively, the correlation analysis between them is performed. The result is depicted in figure 3 , which suggests that ESI-tendency is inversely associated with summer monsoon rainfall over almost all subdivisions of India. This association is statistically significant, at $5 \%$ level, for 14 subdivisions. Area wise, about $49 \%$ of the total area of India shows statistically significant inverse association between ESI-tendency and summer monsoon rainfall. The correlation analysis is further extended to investigate the association between ESI-tendency and different homogeneous regions of India. Figure 4 depicts correlation coefficients between ESI tendency and rainfall over different homogeneous regions of India for the period 1951-2003. It also suggests an inverse relationship of ESI-tendency with all homogeneous regions of India and India as a whole. The relationship is statistically significant, at $5 \%$ level, for all over India, north west India (NWI), central north east India (CNEI), west central India (WCI) and peninsular India (PI). The stability of the inverse relationship is tested by 


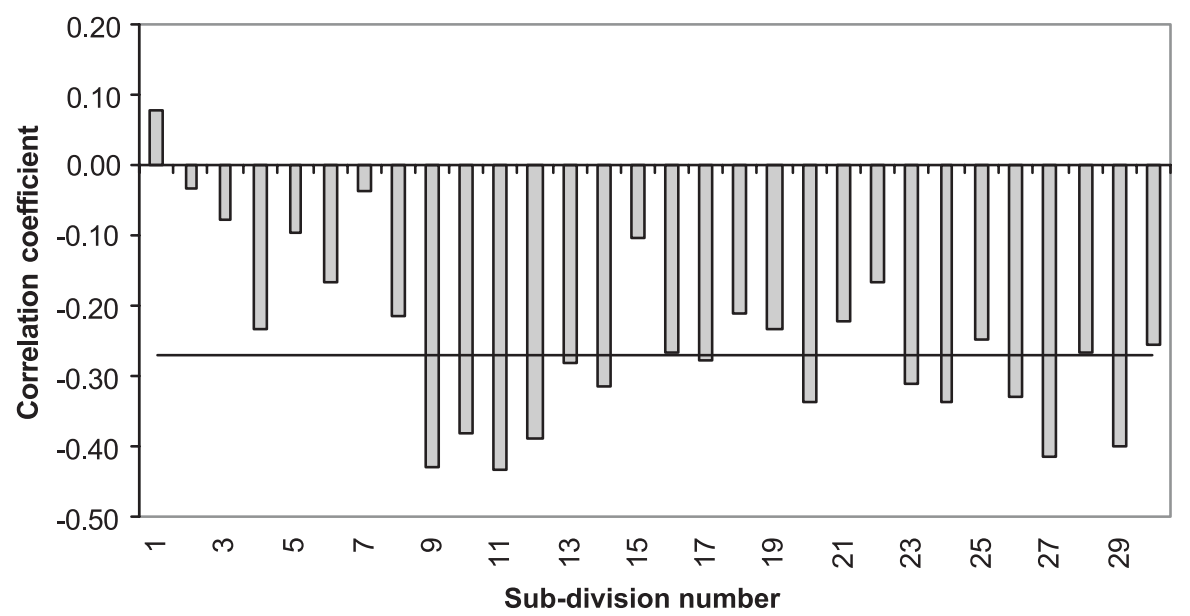

Figure 3. Correlation coefficients between ESI tendency and subdivisional rainfall for 1951-2003. (The horizontal line denotes the $5 \%$ significance level.)

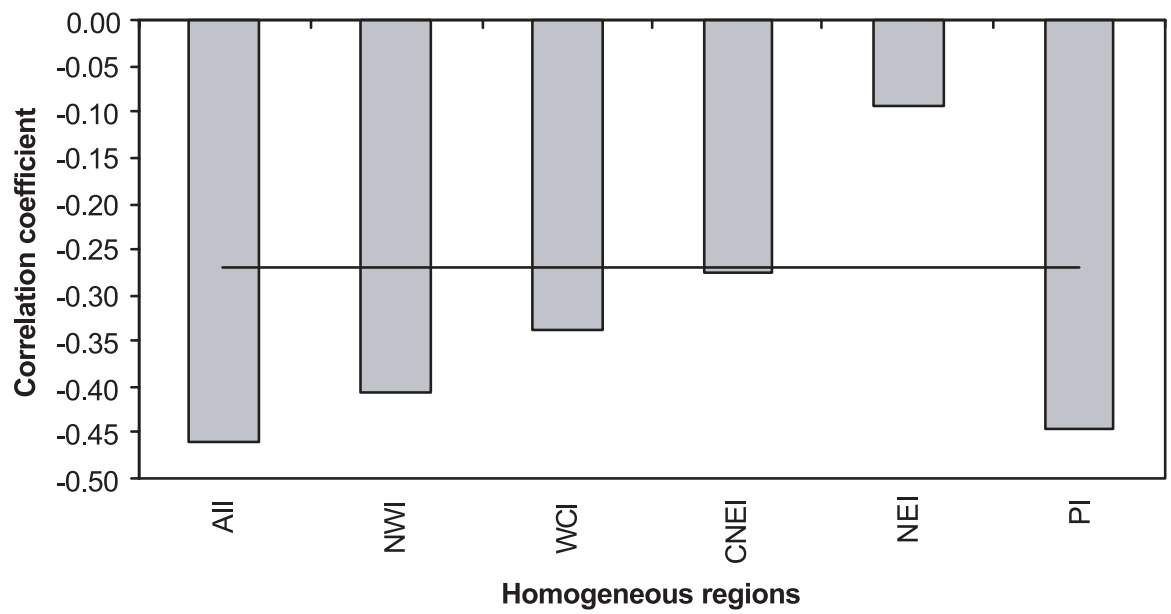

Figure 4. Correlation coefficients between ESI tendency and rainfall over different homogeneous regions of India for 1951-2003. (The horizontal line denotes the 5\% significance level.)

computing 30-year running correlation coefficients between ESI-tendency and summer monsoon rainfall over respective homogeneous regions. Figure 5 shows the same and it suggests that the relationship is inverse in different 30-year periods.

In order to understand the predictive potential of ESI tendency, a simple regression model is developed for predicting percentage rainfall departure over NWI, WCI, PI and India as a whole. For this purpose 30-year data (1961-90) have been used. The bias for these regions and all India is computed and found to be almost zero. Figure 6 depicts the actual and estimated rainfall departure for (a) all India, (b) north west India, (c) west central India and (d) peninsular India, for 19612003. It reveals that for all India and some of its homogeneous regions, these regression equations are underestimating the actual rainfall over respective regions but trend-wise these are catching drought signals very effectively. The correlation coefficients are statistically significant at $1 \%$ level for all India, north west India and peninsular India and at 5\% level for west central India. The skill score (SS), for each regression model, is calculated by the formula $\mathrm{SS}=C / T$, where $C=$ number of years when estimated rainfall value is catching the trend of actual rainfall, $T=$ total number of years. The skill score for the test period 1961-2003 is found to be $0.58,0.65,0.58$ and 0.52 for all India, north west India, peninsular India and west central India respectively. This parameter seems to predict extreme monsoon years (particularly drought years) more effectively. During 1961-2003, there were 6 excess monsoon years $(1961,70,75,83,88$, $94)$ and 11 deficient monsoon years $(1965,66,68$, $72,74,79,82,85,86,87,2002)$. Out of all these 17 extreme monsoon years, all the years except 2 (1970 and 1994), are trend wise well predicted by ESI-tendency. The drought condition during 2002 was well predicted by the ESI-tendency. For this year most of the conventional parameters failed to predict drought conditions over India whereas this 

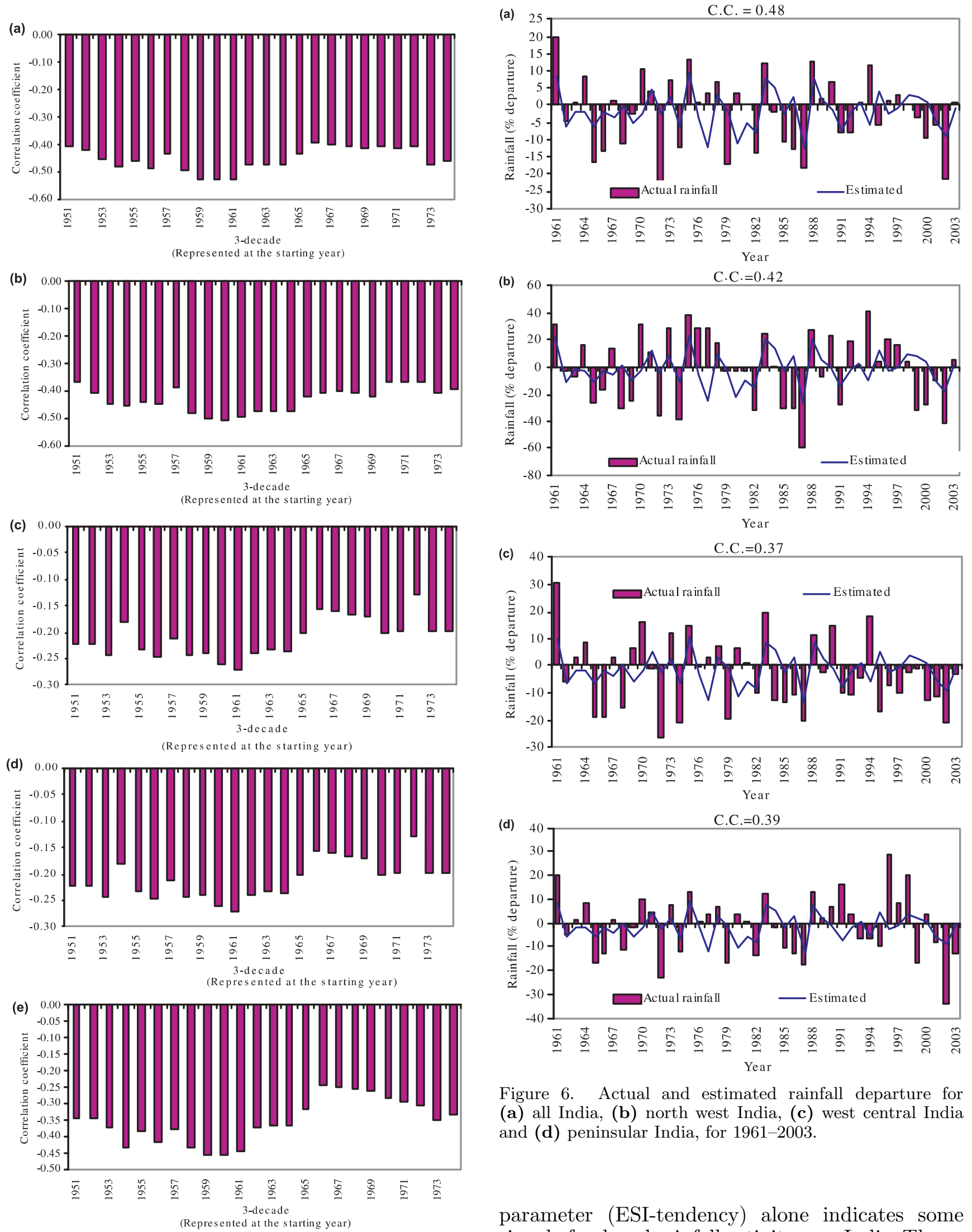

Figure 5. 30-year running correlation coefficients between ESI tendency and rainfall over (a) all India, (b) north west India, (c) central north east India, (d) west central India and (e) peninsular India, for 1951-2003.

Figure 6. Actual and estimated rainfall departure for (a) all India, (b) north west India, (c) west central India and (d) peninsular India, for 1961-2003.

parameter (ESI-tendency) alone indicates some signal of reduced rainfall activity over India. Therefore, we can expect that the use of this parameter in multiple regression models, along with the already existing parameters, may improve our forecasting skill. 


\section{Conclusions}

This study mainly deals with the understanding of simultaneous effect of NAO and SO on Indian summer monsoon rainfall on a smaller spatial scale and the predictive potential of ESI-tendency in forecasting monsoon rainfall activity over the Indian subcontinent. The following conclusions can be drawn from this study:

- Indian summer monsoon rainfall depends upon both the oscillations (NAO and SO) simultaneously. Therefore the joint effect of these two oscillations plays an important role in the summer monsoon circulation over the Indian region. Hence the simultaneous impact of NAO and SO should be considered rather than their individual impact on Indian monsoon rainfall activity.

- The positive tendency of ESI from January to April is linked with the positive phase of ESI during the monsoon season of the year and vice versa. Thus ESI tendency indicates the simultaneous behaviour of NAO and SO during monsoon season.

- The tendency of ESI from January to April can be used as a precursor for predicting Indian summer monsoon rainfall over north west India, west central India, peninsular India and India as a whole.

\section{Acknowledgements}

The authors are grateful to the Director, I.I.T.M. for providing necessary facilities for completing this study and to the Head, Forecasting Research Division for his encouragement and valuable suggestions.

\section{References}

Alexander B P and Elena N V 1992 The NAO and ENSO teleconnection; TOGA Notes 6 10-11.
Chen W Y 1982 Fluctuations in Northern Hemisphere 700 $\mathrm{Mb}$ Height field associated with the southern oscillation; Mon. Wea. Rev. 110 808-823.

Dugam S S, Kakade S B and Verma R K 1997 Interannual and long-term variability in the North Atlantic Oscillation and Indian summer monsoon rainfall; Theor. Appl. Climatol. 58 21-29.

Dugam S S and Kakade S B 1999 Interactive mechanism between ENSO and NAO and its relationship with Indian summer monsoon variability; In: Proc. National Symposium on "Meteorology beyond 2000", TROPMET 99, pp. $53-58$.

Gadgil S, Vinaychandran P N, Francis P A and Gadgil S 2004 Extremes of the Indian summer monsoon rainfall, ENSO and equatorial Indian Ocean Oscillation; Geophys. Res. Lett. 31 doi.10.1029/2004GLOI9733.

Hurrell J W 1996 Influence of variations in extratropical winter time teleconnections on northern hemisphere temperature; Geophys. Res. Lett. 23(6) 665-668.

Kakade S B and Dugam S S 2000 The simultaneous effect of $\mathrm{NAO}$ and $\mathrm{SO}$ on the monsoon activity over India; Geophys. Res. Lett. 7(21) 3501-3504.

Kripalani R H and Kulkarni A 1997 Rainfall variability over South-East Asia - Connections with Indian monsoon and ENSO extremes: New perspectives; Int. J. Climatol. 17 $1155-1168$.

Pant G B and Parthasarathy B 1981 Some aspects of an association between southern oscillation and Indian summer monsoon; Arch. Meteor. Geophys. Biokl. B29 $245-252$.

Rasmusson E M and Carpenter T H 1983 The relationships between the eastern pacific sea surface temperature and rainfall over India and Sri Lanka; Mon. Wea. Rev. 111 $354-384$.

Rogers J C 1984 The association between the NAO and the Southern oscillation in the Northern Hemisphere; Mon. Wea. Rev. 112 1999-2015.

Shukla J, Paolino and Mooley D A 1983 The southern oscillation and long range forecasting of the summer monsoon rainfall over India; Mon. Wea. Rev. 111 1830-1837.

Sikka D R 1980 Some aspects of the large scale fluctuations of summer monsoon rainfall over India in relation to fluctuations in the planetary and regional scale circulation; Proc. Indian Acad. Sci. (Earth Planet. Sci.) 89 179-195.

Verma R K 1990 Recent monsoon variability in the global climate perspective; Mausam 41 315-320.

Van Loon H and Rogers J C 1978 The seasaw in winter temperature between Greenland and Northern Europe Part II: Some oceanic and atmospheric effects in middle and high latitude; Mon. Wea. Rev. 107 509-519. 